\title{
Safe Surgical Plan in Case of Nonlocalized Parathyroid with Thyroid Nodules
}

\author{
Aromal Chekavar ${ }^{1}$, Ajish Thankappan ${ }^{2}$, Sabarethnam Mayilvahanan $^{3}$
}

\begin{abstract}
Papillary thyroid carcinoma increasing in incidence over years. There is always a probability of incidence of papillary thyroid carcinoma in case of primary hyperthyroidism with coexisting thyroid nodules. Among these cases parathyroid adenoma localization with functional imaging is correlated with ultrasonography. In cases of discordant imaging possibility of fine needle aspiration cytology is difficulty and risky. In such a scenario parathyroidectomy with hemithyroidectomy will help in one time procedure which will be curative and guide future treatment.

Keywords: Parathyroid adenoma, Papillary thyroid carcinoma, Parathyroidectomy.

World Journal of Endocrine Surgery (2019): 10.5005/jp-journals-10002-1252
\end{abstract}

\section{INTRODUCTION}

Papillary thyroid carcinoma increasing in incidence over the years. There is always a probability of incidence of papillary thyroid carcinoma in case of primary hyperthyroidism with coexisting thyroid nodules even though coexistence is rare. Here we are describing a case of primary hyperparathyroidism with papillary thyroid carcinoma dealt in a safe surgical plan to avoid overkill and under treatment.

\section{Case Scenario}

A 46-year-old lady came with back pain, shoulder pain, and knee pain for a duration of 10 years and decreased sleep, and she was having irritability and decreased attention for a span of 4 years. On evaluation, she was diagnosed to have primary hyperparathyroidism (corrected calcium $11.1 \mathrm{mg} / \mathrm{dL}, 11 \mathrm{mg} / \mathrm{dL}$, intact PTH (iPTH) $155 \mathrm{pg} / \mathrm{mL}$, and phosphorus-1.9), Tc99 Sestamibi: not identified parathyroid lesion, USG neck-1 $\times$ $0.6 \mathrm{~cm}$ lesion near lower pole, $1 \times 1.2 \mathrm{~cm}$ cystic nodule in the left lobe of thyroid, another $3 \mathrm{~mm}$ hyperechoic nodule posterior

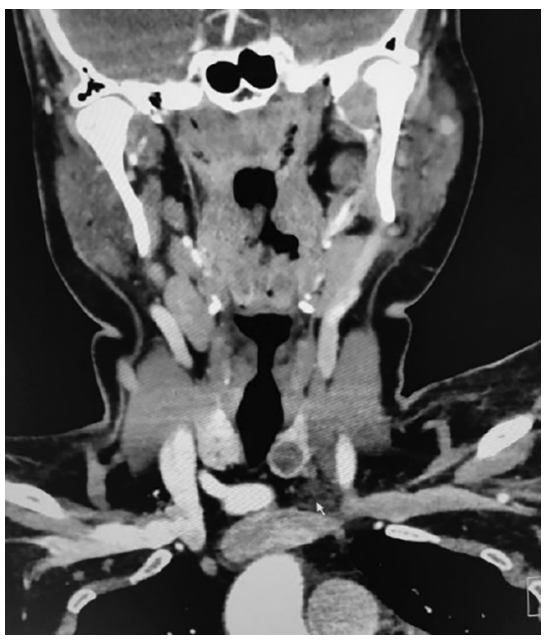

Fig. 1: Preoperative 4D CECT picture depicting suspicious parathyroid and superiorly large thyroid nodule
1,2Travancore Medical College Hospital, Umayanalloor, Kerala, India

${ }^{3}$ Sanjay Gandhi Postgraduate Institute of Medical Sciences, Lucknow, Uttar Pradesh, India

Corresponding Author: Aromal Chekavar, Travancore Medical College Hospital, Umayanalloor, Kerala, India, Phone: +91 9400915216, e-mail: bravearrow2001@yahoo.com

How to cite this article: Chekavar A, Thankappan A, Mayilvahanan S. Safe Surgical Plan in Case of Nonlocalized Parathyroid with Thyroid Nodules. World J Endoc Surg 2019;11(1):31-32.

Source of support: Nil

Conflict of interest: None

to the same nodule, two $0.3 \mathrm{~cm}$ nodules in the right lobe of thyroid, 4D contrast enhanced computerised tomography (CECT)mixed soft tissue lesion inferior pole of the left lobe of thyroid, and similar thyroid lesion described in ultrasonography (USG). In view of negative sestamibi-guided fine needle aspiration cytology (FNAC) not done (In similar cases Figs 1 and 2).

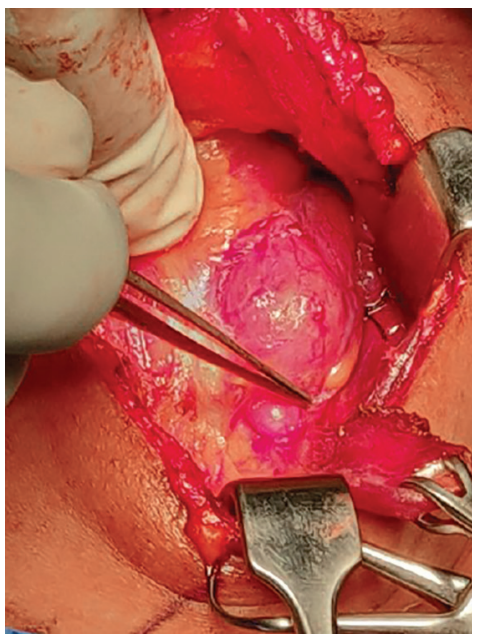

Fig. 2: Intraoperative picture demonstrating parathyroid adenoma and thyroid nodule

() The Author(s). 2019 Open Access This article is distributed under the terms of the Creative Commons Attribution 4.0 International License (https://creativecommons. org/licenses/by-nc/4.0/), which permits unrestricted use, distribution, and non-commercial reproduction in any medium, provided you give appropriate credit to the original author(s) and the source, provide a link to the Creative Commons license, and indicate if changes were made. The Creative Commons Public Domain Dedication waiver (http://creativecommons.org/publicdomain/zero/1.0/) applies to the data made available in this article, unless otherwise stated. 


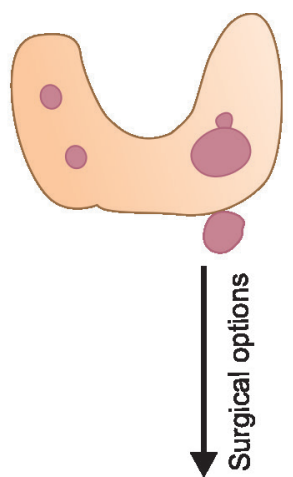

Plan A

Left inferior parathyroidectomy+Lt Hemithyroidectomy

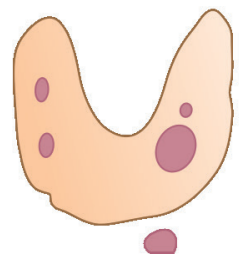

Fig. 3: Surgical plans

\section{Surgical Plan}

Due to the coexistence of thyroid nodules and negative MIBIguided FNAC (Technetium 99 setamibi) was deferred and offered hemithyroidectomy plus focused parathyroidectomy vs focused parathyroidectomy. The patient opted for left inferior parathyroidectomy plus hemithyroidectomy.

Surgery went uneventful. Intraoperative PTH fell more than $80 \%$. The patient recovered with oral calcium and vitamin D supplements. The final histopathology revealed parathyroid adenoma in suspicious extrathyroidal lesion which was inferior to the left lobe, a large $1 \times 1.2 \mathrm{~cm}$ benign colloid nodule in the left lobe, and $0.3 \mathrm{~mm}$ papillary thyroid carcinoma (Fig. 3).

Planning and counseling the patient in prep helped to avoid a high-risk reoperative thyroid surgery and now planning for total thyroidectomy in view of patient concern and the presence of two $0.3 \mathrm{~cm}$ lesions in the opposite lobe with suspicion of micropapillary thyroid carcinoma.

An ideal plan in a similar scenario is to combine hemithyroidectomy along with parathyroidectomy in case of intraoperative parathyroid hormone (IOPTH), showing a curative fall. This will help to achieve optimum surgical cure in similar cases.

\section{References}

1. Vander JB, Gaston EA, et al. The significance of nontoxic thyroid nodules. Final report of a 15-year study of the incidence of thyroid malignancy. Ann Intern Med 1968;69:537-540.

2. Morita SY, Somervell $\mathrm{H}$, et al. Evaluation for concomitant thyroid nodules and primary hyperparathyroidism in patients undergoing parathyroidectomy or thyroidectomy. Surgery 2008;144:862-866. DOI: 10.1016/j.surg.2008.07.029.

3. Kösem $M$, Algün $E$, et al. Coexistent thyroid pathologies and high rate of papillary cancer in patients with primary hyperparathyroidism: controversies about minimal invasive parathyroid surgery. Acta Chir Belg 2004 Oct;104(5):568-571. 